УДК621.791.14.-5

\title{
Control of linear friction welding
}

\author{
A.M. Husnullin ${ }^{1}$, R.M. Kashaev ${ }^{1,2, \dagger}$ \\ †rishat@kashaev.ru \\ ${ }^{1}$ Institute for Metals Superplasticity Problems RAS, 39 Khalturin St., 450001, Ufa, Russia \\ ${ }^{2}$ Ufa State Aviation Technical University, 12 Karl Marx St., 450077, Ufa, Russia
}

\begin{abstract}
Linear friction welding is a relatively new method of joining materials. It is a solid state joining technique, in which significant heat is generated at the faying surfaces of two components under a certain combination of pressure, amplitude and frequency of the relative linear motion. In particular one process, linear friction welding, can be used to join of complex profiles. The linear friction welding process is extremely fast, the whole process could last for several seconds and the control of energy and time parameters is only possible in automatic mode. This paper describes a control system of the linear friction welding mashine. The system is based on a servo-hydraulic testing machine "Schenck", computer and a microcontroller. The linear friction welding cycle consists of compressing two samples to be welded, turning on and off vibrations at a given frequency and amplitude and creation of forging force. The key elements of the welding machine are vibration and compression hydraulic cylinders. The control system synchronizes these hydraulic cylinders and ensures that the linear friction machine operates during the whole welding cycle automatically with pre specified parameters. The control systems of hydraulic cylinders are interconnected and connected with computer via microcontroller. The changes in the burn-off and the friction force are recorded in real time. Desirable levels of precision of the burn-off and the strength of the joint are achieved. We performed several experiments with different materials.
\end{abstract}

Keywords: linear friction welding, controller.

\section{Управление линейной сваркой трением}

\author{
Хуснуллин А.M. ${ }^{1}$, Кашаев P.M. ${ }^{1,2, \dagger}$ \\ †rishat@kashaev.ru
}

\begin{abstract}
${ }^{1}$ Институт проблем сверхпластичности металлов РАН, ул. Халтурина 39, 450001, Уфа, Россия
${ }^{2}$ Уфимский государственный авиационный технический университет, ул. Карла Маркса, 12, 450077, Уфа, Россия
\end{abstract}

\begin{abstract}
Линейная сварка трением - это относительно новый способ соединения материалов в твердом состоянии, в котором значительный разогрев приконтактных областей двух свариваемых деталей происходит при определенной комбинации усилия сжатия, амплитуды и частоты вибрации одной из деталей. В частности, этот метод может быть использован для соединения деталей сложного профиля. Процесс линейной сварки трением чрезвычайно кратковременен, весь цикл сварки может длиться в течении нескольких секунд и управление энергетическими и временными параметрами возможно только в автоматическом режиме. В статье описана система управления лабораторной установки линейной сварки трением. Система создана на базе сервогидравлической испытательной машины “Schenck", персонального компьютера и программируемого контроллера. Цикл линейной сварки трением включает: создание усилия сжатия между двумя свариваемыми деталями, включение и выключение вибрации с заданной частотой и амплитудой и создание усилия проковки. Ключевыми элементами установки являются гидроцилиндр вибрации и гидроцилиндр усилия сжатия. Система управления обеспечивает синхронную работу этих гидроцилиндров, чтобы установка линейной сварки трением отрабатывала весь цикл сварки в автоматическом режиме, по заранее введенным параметрам. Управляющие системы гидроцилиндров связаны между собой и персональным компьютером единой схемой на основе контроллера управления. В памяти компьютера регистрируются также изменение величины и усилия осадки в режиме реального времени. При сохранении неизменности основных параметров процесса была обеспечена как необходимая величина осадки, так и прочность соединения. На созданной установке проведены эксперименты по сварке трением различных материалов.
\end{abstract}

Ключевые слова: линейная сварка трением, контроллер управления. 
Сварка трением широко применяется в различных отраслях производства, в частности в машиностроении. Процесс обеспечивает высокое качество сварного соединения металлов и сплавов без их расплавления, характеризуется высокой производительностью, экономичен, не требует применения каких-либо расходуемых сварочных материалов, а также защитной среды [1]. В настоящее время существует несколько разновидностей сварки трением, которые отличаются возможностями применения и конструктивным исполнением оборудования. Наиболее широко известен способ сварки трением, при котором тепловая энергия генерируется вращением соединяемых осесимметричных деталей относительно друг друга. В отличие от этого способа линейная сварка трением (или «вибрационная сварка» [1]) предназначена для соединения неосесимметричных деталей. Схема процесса представлена на рис. 1. Нагрев производится за счет работы сил трения при возвратнопоступательном перемещении относительно друг друга соединяемых деталей (показано вертикальными стрелками), прижатых с определенным усилием $F$.

В результате нагрева снижается сопротивление деформации металла приконтактных слоев и под действием усилия прижатия $F$ пластифицированный металл выдавливается из зоны контактных поверхностей на периферию за пределы этой зоны, образуя грат, выносящий из стыка возможные дефекты и загрязнения.

Однако, если для сварки с относительным вращением свариваемых заготовок, создана целая серия специализированных машин [1], то оборудование для линейной сварки трением в России не производится, а установки, произведенные за рубежом чрезвычайно дороги, что связано со сложностью технической реализации, прежде всего, линейных (возвратно-поступательных) колебаний подвижной свариваемой детали. Отсутствие специализированного оборудования сдерживает не только освоение этой инновационной технологии промышленностью, но и исследования в этой области.

Авторами разработана и на базе сервогидравлической испытательной машины «Schenck» реализована лабораторная установка линейной сварки трением. Внешний вид установки показан на рис. 2.

Основными функциональными блоками в установке являются:

- привод вибрации подвижной детали;

- привод усилия прижатия друг к другу соединяемых деталей;

- устройства жесткой фиксации и точного позиционирования соединяемых деталей;

- система управления и контроля процесса.

Гидроцилиндр вибрации и гидроцилиндр для создания усилия сжатия между соединяемыми деталями, на штоках которых крепятся зажимные устройства для свариваемых деталей, расположены перпендикулярно друг к другу. Процесс сварки чрезвычайно кратковременный, поэтому управление процессом сварки возможно только в автоматическом режиме. Система управления лабораторной установки обеспечивает автоматическую синхронную работу обоих гидроцилиндров, когда весь цикл сварки: создание усилия сжатия между соединяемыми деталями, включение вибрации с заданной частотой и амплитудой и ее выключение после заданного времени, создание усилия проковки, происходит в автоматическом режиме, по заранее введенным параметрам, без участия человека. На созданной установке проведены эксперименты по сварке трением различных материалов с получением высококачественных соединений [2-5].

Структурная схема управления линейной сваркой трением представлена на рис. 3.

Система управления линейной сваркой трением включает собственно установку сварки трением, содержащий объект управления в виде двух управляемых гидроцилиндров, один из которых генерирует вибрацию, а другой усилие $F$. Состояние объекта управления определяется следующими датчиками:

- датчик положения ДП1, датчик положения ДП2;

- датчик усилия ДУ1.

Непосредственное управление осуществляется установкой «Schenck», в которой выполняются усиление и преобразование сигналов с датчиков, сравнение с заданными сигналами управления по усилию, по положению, а также задается частота вибрации исполнительного механизма ИМ2.

Контроллер управления выдает с выхода ЦАП1 сигнал управления исполнительному механизму ИМ1 в виде усилия сжатия, преобразует аналоговые значения с датчиков положения ДП1 и датчика усилия ДУ1 и передает в компьютер для последующей их регистрации, а также обеспечивает синхронную работу двух исполнительных механизмов ИМ1 и ИМ2. Синхронность заключается в том, что после приложения заданного усилия, включается вибрация ИМ2, отсчитывается заданное время, после отсчета прекращается вибрация, фиксируется положения ИМ1 и включается усилие проковки.

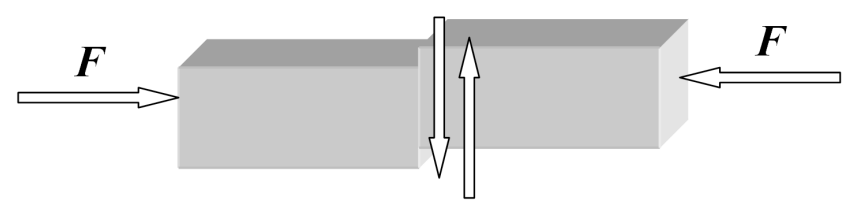

Pис. 1. Схема линейной сварки трением.

Fig. 1. Linear friction welding scheme.

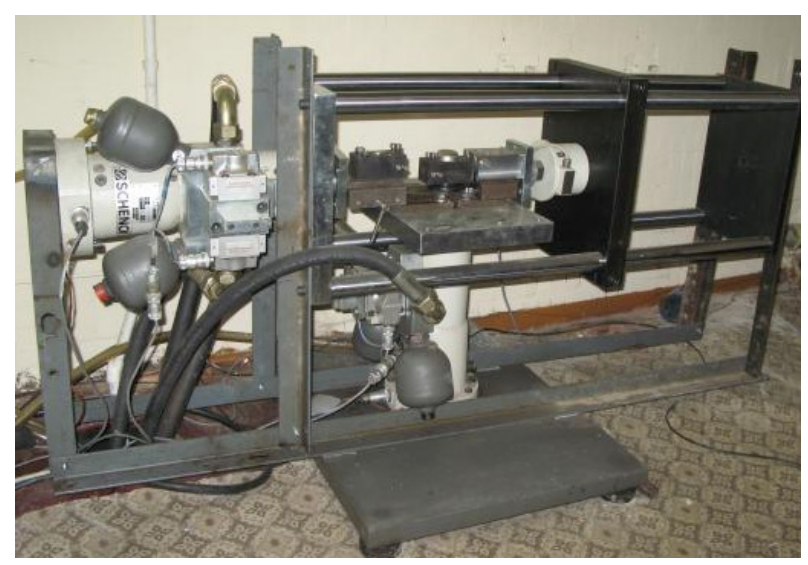

Рис. 2. Установка линейной сварки трением.

Fig. 2. Linear friction welding machine. 


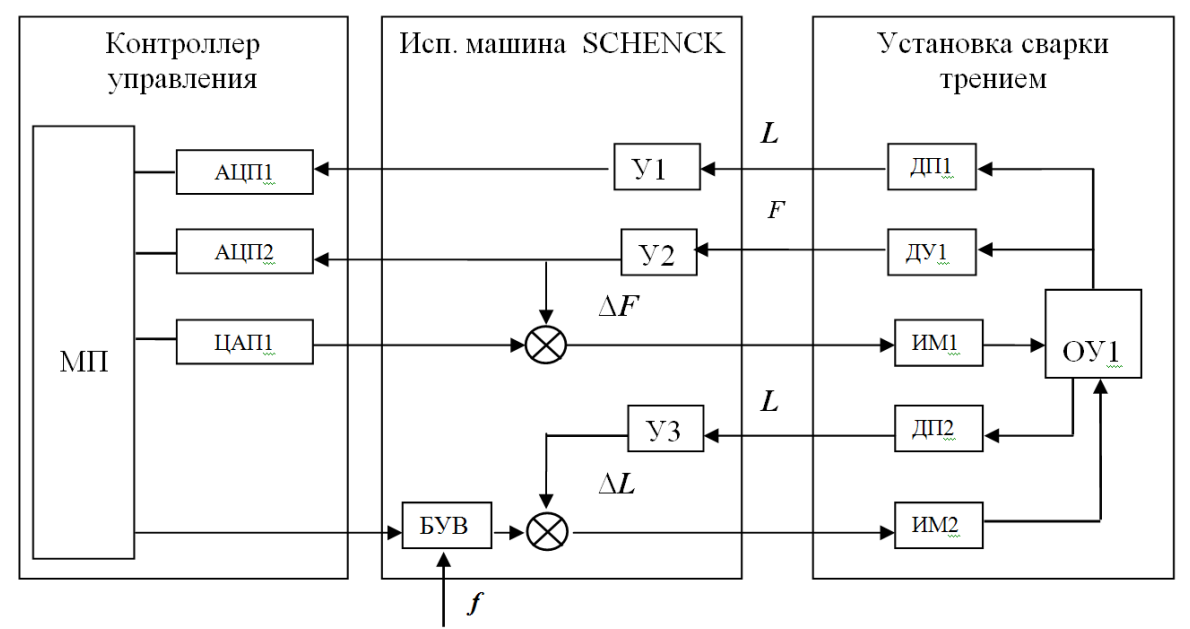

МП - микропроцессор РІС16F876А.

АЦП1, АЦП2 - аналого-цифровой преобразователь AD7705. ЦАП1 - цифроаналоговый преобразователь.

У1, У2, У3 - усилители-нормализаторы сигналов с датчиков. БУВ - блок управления вибрацией.

ДП1, ДП2 - датчики положения механизма - индуктивный датчик РFM 40.

ДУ 1 - тензометрический датчик усилия РМ 63 KN.

ИМ1, ИМ2 - исполнительный механизм гидроцилиндр PL 63. ОУ1 - обьект управления.

$f$ - задание частоты вибрации.

Рис. 3. Структурная схема управления линейной сваркой трением.

Работа установки происходит следующим образом (рис. 4). После установки и закрепления свариваемых деталей, предварительно с пульта задаем значения амплитуды и частоты вибрации, значения усилий сжатия и проковки и время сварки. Запускаем процесс сварки включением вибрации предварительно сжатых свариваемых деталей. Начинается нагрев контактных поверхностей деталей за счет силы трения. После отсчета заданного значения времени, вибрация отключается, и прикладывается усилие проковки. После окончания цикла сварки усилие снимается.

Стабильность качества соединений, выполненных сваркой трением, можно гарантировать, если выполняются следующие условия: точно определен момент перехода от нагрева к проковке; своевременно выявлены несоответствия основных параметров сварки задаваемым. Поэтому, исключительно важное значение приобретает запись основных параметров процесса во времени при сварке каждой детали. На циклограмме рис. 5 показано изменение величины и усилия осадки в режиме реального времени при линейной сварке трением титанового сплава ВТ9 (вибрация подвижной заготовки с частотой 30 Гц и амплитудой 1,5 мм).

Были проведены эксперименты по сварке титанового сплава ВТ9 и нержавеющей стали X18H10T.

Для оценки качества сварного соединения проводили испытания на ударный изгиб образцов сечением 6 мм на 10 мм и длиной 55 мм с U-образным надрезом радиусом 1 мм в месте соединения. Ударная вязкость соединений как титанового сплава ВТ9, так и нержавеющей ста-
MП - microcontroller PIC16F876A.

АЦП1, АЦП2 - analog/digital converter AD7705.

ЦАП1 - digital/analog converter.

У1, У2, У3 - signal amplifiers.

БУВ - vibration control unit.

ДП1, ДП2 - inductive position sensor PFM 40.

ДУ1 - load cell PМ 63 KN.

ИМ1, ИМ2 - hydraulic cylinder PL 63.

Oy1 - control object.

$f$ - vibration frequency setting.

Fig. 3. Block diagram of control unit.

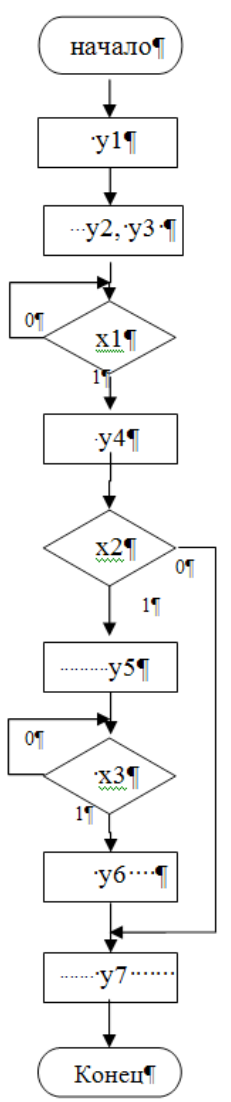

у1 - установка свариваемых деталей

у2 - обеспечение постоянного усилия сжатия

у3 - включение вибрации

у4 - отключить вибрацию

у5 - включить усилие проковки

у6 - отключить усилие проковки

у7 - контроль сварного соединения

$\mathrm{x} 1$ - время сварки больше заданного?

х2 - требуется ли усилие проковки после окончания вибрации?

х3 - время действия усилия проковки больше заданного?

y1 - insert the samples

y2 - ensuring constant compression force

y3 - switching on vibration

y4 - switching off vibration

y5 - switching on forging force

y6 - switching off forging force

y7 - weld inspection

$\mathrm{x} 1$ - welding time greater than the set?

$\mathrm{x} 2-$ is forging force necessary?

$\mathrm{x} 3$ - forging force time greater than the set?

Рис. 4. Блок-схема системы управления.

Fig. 4. The flow chart of the control system. 


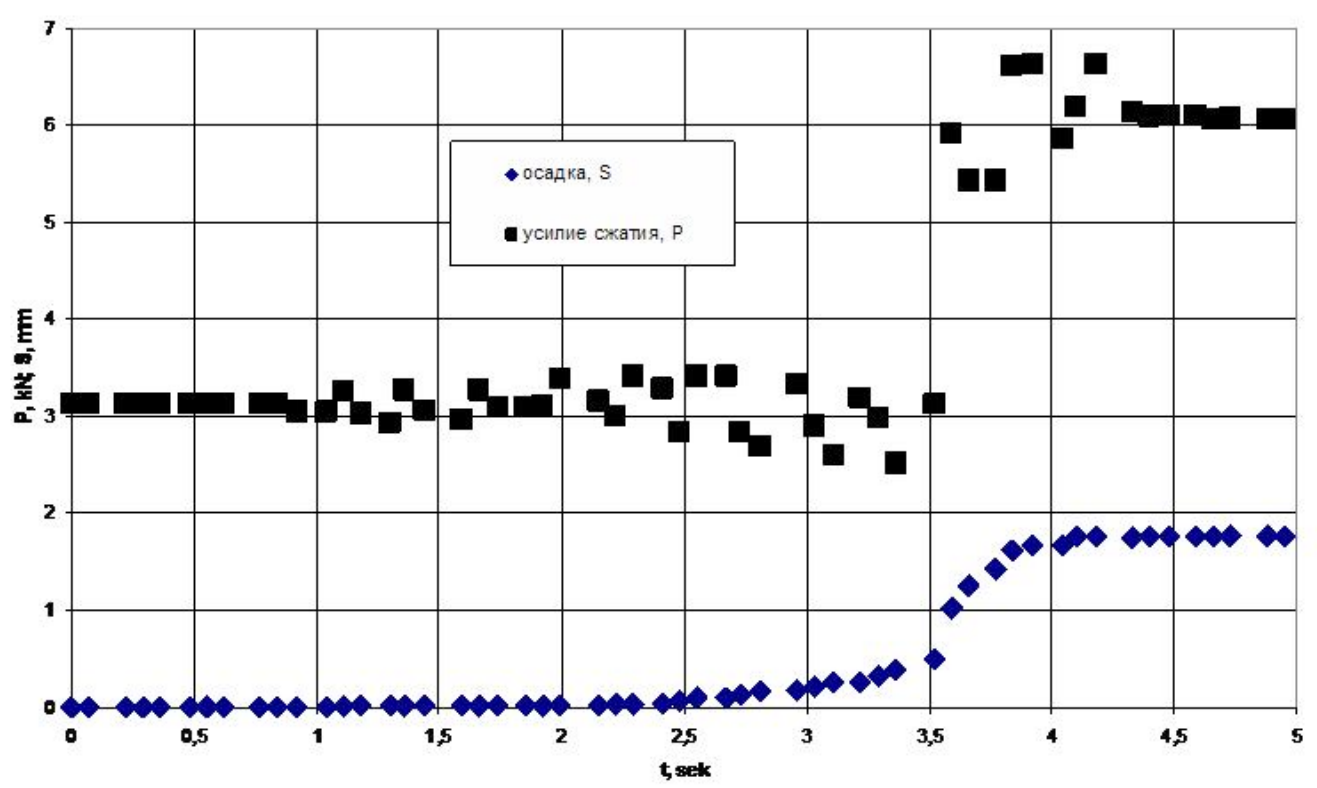

Pис. 5. Циклограмма процесса линейной сварки трением сплава BT9[2].

Fig. 5. The variation of the linear friction weld parameters with time of titanium alloy VT9[2].

ли Х18H10T, выполненных линейной сваркой трением составила не менее $80 \%$ от ударной вязкости основного металла. Разрушение при испытании на статическое растяжение гладких цилиндрических десятикратных образцов диаметром 3 мм произошло по основному металлу, вне зоны соединения.

При сохранении неизменности основных параметров процесса (частоты и амплитуды вибрации, усилия сварки (нагрева), времени сварки (нагрева) и усилия проковки) была обеспечена как необходимая величина осадки, так и прочность соединения.

Таким образом, система управления лабораторной установкой линейной сварки трением на основе программируемого контроллера позволяет получать качественные соединения, а также расширяет функциональные возможности установки.

\section{Литература/References}

1. V. I. Vil. Friction welding of metals. Moskow, (1970) 169 p. (in Russian) [Вилль В.И. Сварка металлов трением. М.: Машиностроение, 1970. 169 c.]

2. R. M. Kashaev, A. M. Husnullin, V. V. Nikolaev. Metal Week in Moscow 2008. Materials of Conferences. Moscow. (2009) p.121 - 126. (in Russian) [Р. М. Кашаев, А. М. Хуснуллин, В.В. Николаев. Неделя металлов в Москве 2008. Сб. трудов конференций. М. 2009 г. с. 121 - 126].

3. R.M. Kashaev, A.M. Husnullin, V.V. Nikolaev. Gas Turbo Technology. Issue 2. (2009). p. 24 -29. (in Russian) [Р. М. Кашаев, А. М. Хуснуллин, В. В. Николаев. О линейной сварке трением блиска компрессора ГТД. Газотурбинные технологии, № 2, 2009 г., с.24 - 29].

4. A.A. Zakirova, M.I. Nagimov, A.M. Husnullin, R.M. Kashaev. Perspektivnye materialy, № 12. (2011). p.155-160. (in Russian). [А.А. Закирова, М.И. Нагимов, А.М. Хуснуллин, Р.М. Кашаев. Структура, свойства и горячая деформация сварного соединения 08X18Н10Т, полученного линейной сваркой трением (ЛСТ) // Перспективные материалы. 2011. Спец. вып. № 12. С 155 - 160].

5. E.A. Abramova, G.F. Korznikova, A. V. Korznikov, A.M. Husnullin, V.V. Nikolaev, R.M. Kashaev. Letters on Materials. № 1 (2015).p.90 - 93 (in Russian) [Е.А. Абрамова, Г.Ф. Корзникова, А.В. Корзников, А.М. Хуснуллин, В.В. Николаев, Р.М. Кашаев. Микроструктура и механические свойства сварного соединения магнитотвердого сплава $25 \mathrm{X} 15 \mathrm{~K}$ со сталью 10880 полученного линейной сваркой трением // Письма о материалах. 2015. № 1. С. 90 -93]. 